\title{
A gain-of-function screen to identify genes that reduce lifespan in the adult of Drosophila melanogaster
}

Minoru Nakayama ${ }^{1,5}$, Tomoki Ishibashi ${ }^{2}$, Hiroyuki O Ishikawa ${ }^{1,6}$, Hiroyasu Sato ${ }^{3}$, Takao Usui ${ }^{3}$, Takayuki Okuda ${ }^{3}$, Hiroyuki Yashiro ${ }^{3}$, Hironori Ishikawa ${ }^{3}$, Yoshie Taikou ${ }^{3}$, Asako Minami ${ }^{3}$, Kengo Kato ${ }^{3}$, Masataka Taki ${ }^{3}$, Toshiro Aigaki ${ }^{4}$,

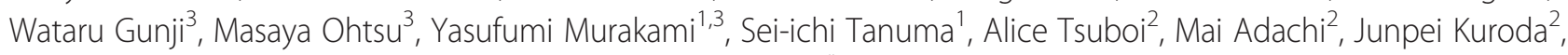
Takeshi Sasamura², Tomoko Yamakawa² and Kenji Matsuno ${ }^{2^{*}}$

\begin{abstract}
Background: Several lines of evidence associate misregulated genetic expression with risk factors for diabetes, Alzheimer's, and other diseases that sporadically develop in healthy adults with no background of hereditary disorders. Thus, we are interested in genes that may be expressed normally through parts of an individual's life, but can cause physiological defects and disease when misexpressed in adulthood.

Results: We attempted to identify these genes in a model organism by arbitrarily misexpressing specific genes in adult Drosophila melanogaster, using 14,133 Gene Search lines. We identified 39 "reduced-lifespan genes" that, when misexpressed in adulthood, shortened the flies' lifespan to less than $30 \%$ of that of control flies. About half of these genes have human orthologs that are known to be involved in human diseases. For about one-fourth of the reduced-lifespan genes, suppressing apoptosis restored the lifespan shortened by their misexpression. We determined the organs responsible for reduced lifespan when these genes were misexpressed specifically in adulthood, and found that while some genes induced reduced lifespan only when misexpressed in specific adult organs, others could induce reduced lifespan when misexpressed in various organs. This finding suggests that tissue-specific dysfunction may be involved in reduced lifespan related to gene misexpression. Gene ontology analysis showed that reduced-lifespan genes are biased toward genes related to development.

Conclusions: We identified 39 genes that, when misexpressed in adulthood, shortened the lifespan of adult flies. Suppressing apoptosis rescued this shortened lifespan for only a subset of the reduced-lifespan genes. The adult tissues in which gene misexpression caused early death differed among the reduced-lifespan genes. These results suggest that the cause of reduced lifespan upon misexpression differed among the genes.
\end{abstract}

Keywords: Genetic screen, Drosophila, Apoptosis, Reduced lifespan, Gene misexpression

\section{Background}

Major risk factors for late-onset sporadic diseases such as diabetes, inflammation, neurodegeneration, and cancer are believed to include aging, unhealthy lifestyles, and various stresses [1-3]. However, the molecular mechanisms that increase morbidity in these diseases are not completely understood. Shortened telomeres is a factor in cellular

\footnotetext{
* Correspondence: kmatsuno@bio.sci.osaka-u.ac.jp

${ }^{2}$ Department of Biological Sciences, Osaka University, 1-1 Machikaneyama,

Toyonaka, Osaka 560-0043, Japan

Full list of author information is available at the end of the article
}

aging and genomic instabilities, and could increase susceptibility to cancer [3]. It has also been proposed that gene expression levels are altered by aging or various stresses, and these changes may account for triggers or risk factors of late-onset diseases. For example, Calpain, a $\mathrm{Ca}^{2+}$ activated cysteine protease that accumulates in the brain of Parkinson's disease patients [4], is induced by various stimuli including oxidative stress [5]. Upregulated Calpain activity has also been linked to neurodegenerative diseases such as Alzheimer's disease and Parkinson's disease $[4,6]$. Alterations in gene expression levels in response to age or
C Bïomed Central

(c) 2014 Nakayama et al.; licensee BioMed Central Ltd. This is an Open Access article distributed under the terms of the Creative Commons Attribution License (http://creativecommons.org/licenses/by/2.0), which permits unrestricted use, distribution, and reproduction in any medium, provided the original work is properly credited. 
stress have been observed in model animals; in the mouse brain, for example, several genes involved in immune or inflammatory responses are upregulated with aging [7]. In Drosophila, the expression levels of many genes change with aging and in respond to oxidative stress [8]. However, the potential impact of these changes remains to be clarified, even in these model organisms.

The Drosophila melanogaster genome project revealed that $61 \%$ of the known human disease genes are conserved between humans and Drosophila $[9,10]$. The short life cycle and the powerful tools for genetic and molecular analysis available in Drosophila make this species an advantageous model for studying the functions of genes associated with various human diseases $[11,12]$. In particular, mutants of Drosophila homologs of human disease genes allow us to study the developmental, cellular, and molecular functions of these genes [13,14]. For example, Drosophila models of Parkinson's disease have provided important insights into the relationships among genes that mediate this disease in humans [15]. However, most studies of mutations in Drosophila homologs of human disease genes have focused on developmental defects.

Since genes that strongly affect physiology and homeostasis when their expression levels are altered could account for the increasing morbidity rate of late-onset diseases in humans, and expression levels can be altered by aging and other stresses, it is worthwhile to examine the impact of changes in gene expression at the adult stage of model organisms such as Drosophila. The consequences of genetic perturbations that occur after reaching adulthood may help us understand how aberrant gene expression relates to the appearance of late-onset defects and loss of longevity. Therefore, using the Drosophila system, we attempted to identify genes that reduce lifespan when misexpressed only in adulthood.

The Drosophila gene search (GS) line allows us to spatially and temporally control the expression of specific genes in the genome [16]. Gain-of-function screens using the GS system have revealed new components in biological processes such as the determination of tissue identity, neural cell death, neural development, and longevity [17-21]. Here, using the GS system, we identified and characterized 39 genes that severely reduced longevity when misexpressed in adulthood.

\section{Results and discussion Primary screen}

This study was designed to identify genes that severely reduced the Drosophila lifespan when misexpressed in adulthood. To accomplish this, we arbitrarily misexpressed genes in adult flies from various GS lines [16]. Each GS line carries a GS vector, an engineered Drosophila transposon that carries a promoter (GS promoter) controlled by the UAS. The GS promoter contains binding sites for a yeast transcription factor, GAL4 [22]. The GS promoter is activated in the presence of GAL4, and its transcription activity is negligible without GAL4 [22]. Because the GS vector does not have a transcription terminator sequence, mRNA precursor synthesis continues through the endogenous gene next to the GS vector insertion site. Thus, in each GS line, one endogenous gene-which can be predicted based on the GS vector insertion site-is misexpressed in a GAL4-dependent manner [16]. In this study, we screened 14,133 GS lines with the potential to misexpress 4,605 genes (DGSP, http://gsdb.biol.se.tmu.ac.jp/ dclust/).

To misexpress arbitrary genes specifically in adult flies, we maintained GS vector-bearing flies at $18^{\circ}$ until eclosion to suppress $h s$-GAL4 expression during development, and then induced $h s$-GAL4 in the adult flies by heat-shocking at $37^{\circ} \mathrm{C}$ for $20 \mathrm{~min}$ (Figure $1 \mathrm{~A}$ ), thus inducing the GAL4driven misexpression of specific genes (Figure 1A). However, leaky expression from some of these GS lines could not be excluded under these conditions.

Before beginning a large-scale screening of GS lines, we tested the effects of heat-shock on the longevity of adult flies to distinguish them from the effects of gene misexpression. We randomly picked up 122 GS lines and crossed them with $h s$-GAL4 flies. For each line, we collected between 20 and $40 \mathrm{~F} 1$ males and divided them into two groups. One group was heat-shocked at $37^{\circ}$ for $20 \mathrm{~min}$ at 2 to 7 days after eclosion, and then maintained at $25^{\circ}$. The other group was kept at $25^{\circ}$ without heat-shock treatment. The mean lifespan of the adult flies with or without heatshock treatment was $55.2 \pm 0.9$ and $56.6 \pm 0.9$ days ( \pm denotes SEM), respectively (Figure $2 \mathrm{~A}$ ); we could not find a significant difference between the groups using the t-test (Figure 2C), and the difference between the two groups was very small or negligible (the $95 \%$ confidence interval for the difference was -3.9 to 1.0 days). Therefore, the heat-shock treatment used in this study had no general effect on the longevity of the adult flies.

Using the heat-shock treatment described above, we next conducted a genome-wide screen to identify genes that severely reduced longevity when misexpressed in adulthood. As the primary screen, we selected GS lines in which more than $80 \%$ of the individual adult flies died within 5 days after misexpression of the genes. In this screen, newly eclosed F1 males were collected for 5 days at $18^{\circ}$, heat-shocked at $37^{\circ}$ for $20 \mathrm{~min}$, and then cultured for another 5 days at $25^{\circ}$; the 5 -day period corresponded to less than $10 \%$ of the mean longevity of control GS flies (55.2 \pm 0.9 days) under these conditions (Figure 2A).

We crossed 14,133 GS lines with $h s$-GAL4 flies. We recovered about ten F1 males from each of 12,768 GS lines, although for a few of these lines, tests were conducted using fewer flies (at least four) because of the difficulty of obtaining F1 adults in these lines. We could not recover F1 flies from crosses involving 1,365 of the GS lines. In 

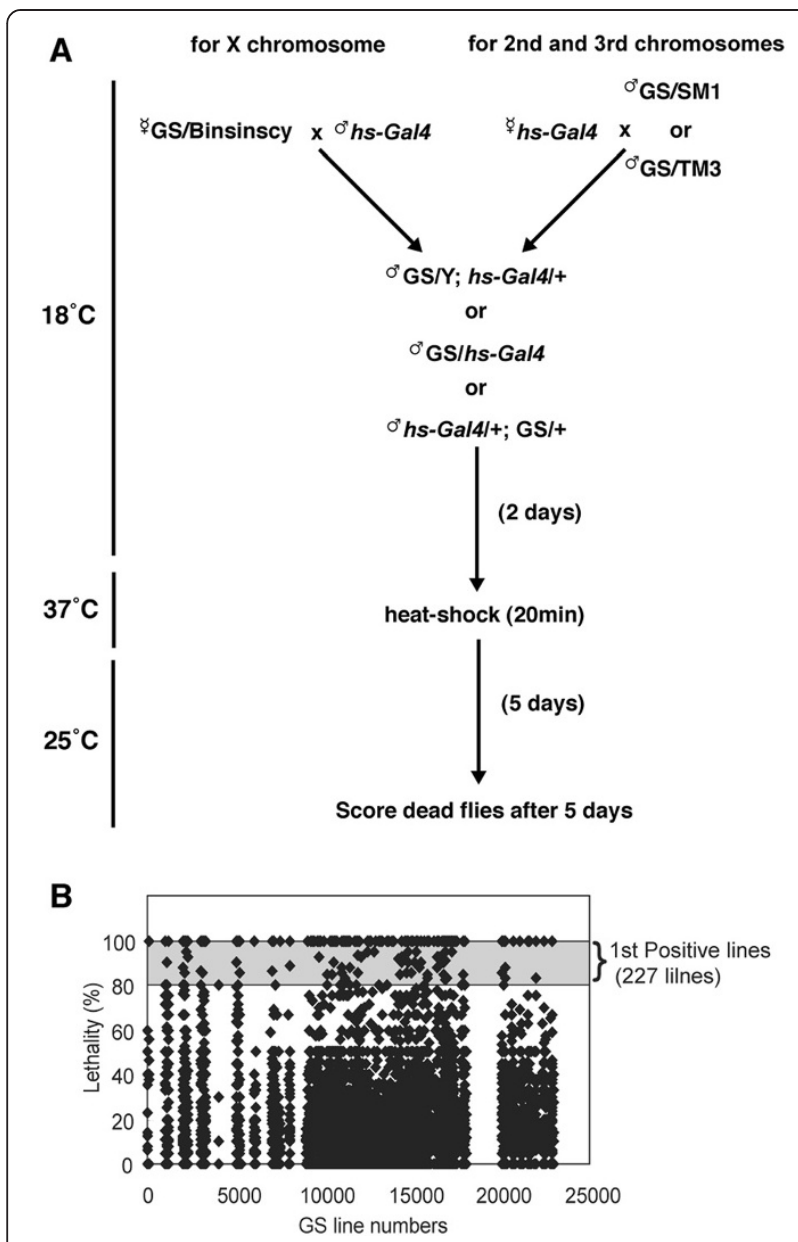

Figure 1 A gain-of-function screen to identify reduced-lifespan genes. (A) Crosses for the primary screen: GS lines were crossed with $h s-G A L 4$, and their $F 1$ progeny were raised, at $18^{\circ}$. Typically, 10 to $20 \mathrm{~F} 1$ adult males carrying each GS vector and $h s-G A L 4$ were collected for 5 days after eclosion, reared for another 2 days at $18^{\circ}$, and then heat-shocked at $37^{\circ}$ for $20 \mathrm{~min}$. The flies were reared for another 5 days at $25^{\circ}$, and then dead flies were counted. Lethality was calculated as the percentage of total heat-shocked flies that were dead flies. (B) A dot plot showing the lethality (determined by the percentage of survivors 5 days after heat shock) of individual lines; the shaded area in the graph corresponds to $80-100 \%$ lethality. GS lines with lethality greater than $80 \%$ (227 lines, indicated as $1^{\text {st }}$ positive lines) were used for a secondary screen.

these cases, we speculate that leaky $h s$-GAL4 expression may have driven the GAL4-dependent expression of the GS vector-regulated gene even at $18^{\circ}$, causing lethal developmental defects. Some of these genes might strongly affect biological processes related to cell physiology and function. However, because it could be difficult to distinguish quickly whether lethality was due to developmental defects such as cell-specification and developmental pattern formation, or due to general defects in cell physiology and functions, which we were interested in, we did not study these genes further. In total, we screened 12,768 GS lines. The genes expressed in each GS line were predicted based on the GS vector insertion site (DGSP, http://gsdb. biol.se.tmu.ac.jp/ dclust/).

In Figure 1B, the lethality of individual lines, determined by the percentage of survivors 5 days after heat shock, is indicated by a dot plot. Gene misexpression in 12,541 of the GS lines screened ( $98.2 \%$ of the total) did not severely reduce adult longevity; in these lines, more than $80 \%$ of the individual flies were still alive 5 days after heat-shock treatment (Figure 1B). However, in 227 of the GS lines we screened ( $1.8 \%$ of the total), the lifespan was significantly reduced after heat-shock treatment; less than $20 \%$ of the individual flies were still alive 5 days after heat-shock treatment (Figure 1B). In this screen, some genes were repeatedly identified in independent GS lines. For example, we identified eight independent GS lines misexpressing Heterogeneous nuclear ribonucleoprotein at 27C. In total, 23 genes were identified twice or more times, although six of these were excluded by the secondary screening (see below). These results suggest that acutely reduced longevity is a specific phenotype caused by the misexpression of a small number of genes, although the underlying mechanisms of these phenomena might differ between cases.

\section{Secondary screen}

In the primary screen, we selected GS lines based on lethality measured 5 days after the heat-shock treatment. However, it was possible that this lethality was caused by developmental defects associated with leaky gene expression before adulthood. To determine whether the lethality was due to gene misexpression in the adult stage, we next compared the mean longevity of heat-shocked flies versus those not subjected to heat-shock within individual lines.

Our secondary screen analyzed 197 of the 227 positive GS lines identified in the primary screen (the remaining lines were no longer available). These GS lines were crossed with $h s$-GAL4 lines as in the primary screen, 10 to 20 F1 males were collected for each lifespan measurement, and the mean longevity of each population was measured with or without heat-shock treatment. We compared the lifespan of these adult flies with or without heat shock, and we selected GS lines in which heat shock reduced the longevity to less than $30 \%$ of that in the same line without heat shock. Based on this criterion, we obtained 47 GS lines in which heat shock significantly reduced the mean lifespan (Additional file 1: Table S1). Lines that were selected in the primary screen but did not meet the more stringent criteria of the second screen were considered GS negative. These lines may have shown a loss of longevity in the primary screen due to leaky gene expression.

The 47 positive GS lines identified in the second screen were found to drive 39 reduced-lifespan genes (see Table 1) that, when misexpressed in adulthood through heat shock, reduced the longevity to less than $30 \%$ of that of flies not subjected to heat shock (control). Figure 2B shows the 

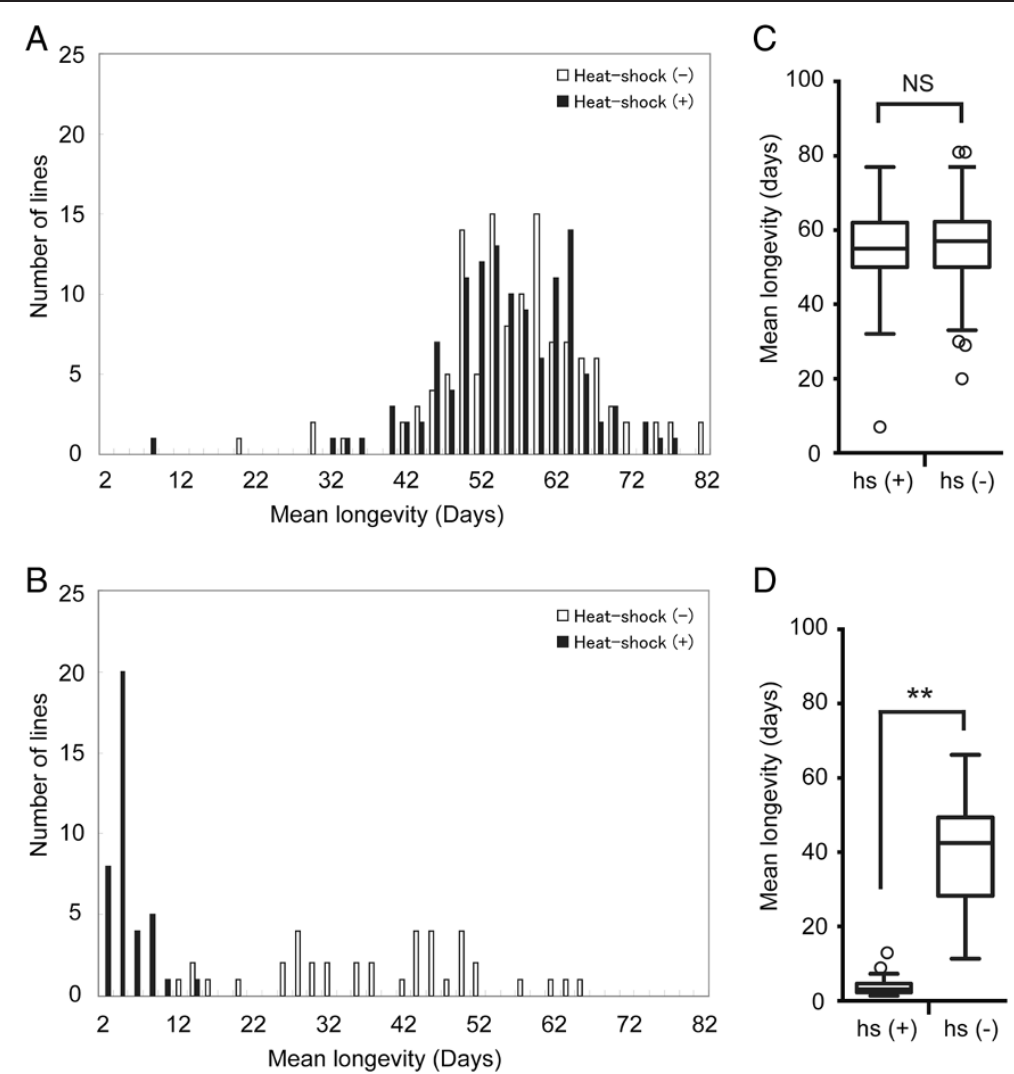

Figure $\mathbf{2}$ Comparison of the mean longevity of F1 progeny with or without heat shock. (A and B) The mean longevity of F1 progeny carrying each GS vector and hs-GAL4 was measured with or without heat shock. The numbers of GS lines with the indicated mean longevity are shown for each 2-day period. White and black bars correspond to the number of GS lines treated without (-) or with (+) heat shock, respectively. (A) Mean longevity averages for 122 randomly selected GS lines: the average mean longevity of flies treated without or with heat-shock was 56.6 and 55.2 days, respectively. (B) GS lines misexpressing reduced-lifespan genes, identified from the screen. The average of the mean longevities of flies that were or were not heat-shocked was 3.7 and 38.5 days, respectively. (C and D) Box-and-whisker plots of the mean longevity averages for 122 randomly selected GS lines $(\mathbf{C})$ and lines with reduced-lifespan genes (D), with (+) or without (-) heat shock (hs). Whiskers and outliers were determined by Tukey's method. Significance indicated $\left(^{* *}\right)$ is $P<0.001$ (unpaired t-test). NS: not significant.

mean lifespan with or without heat-shock treatment for selected positive GS lines, each expressing a reduced-lifespan gene (see Table 1). Box-and-whisker plots showed a striking difference in survival between the untreated and heat-shocked groups of these positive GS lines (Figure 2D). For example, Transportin misexpression in adult flies reduced their mean longevity to $3 \%$ of that of the control flies (Table 1). About half of the reduced-lifespan genes identified in this study have human orthologs that have been linked directly or indirectly to human disease (Table 2).

The misexpression of Drosophila genes using the GAL/UAS system is well established [22]. In addition, we here used semi-quantitative RT-PCR to confirm the misexpression of genes from GS insertions upon heat shock; the reduced-lifespan genes were markedly induced in 6 out of 8 arbitrarily selected positive GS lines (Additional file 2: Figure S1).

\section{Reduced-lifespan gene misexpression may reduce longevity through apoptosis}

We next studied how the misexpression of these reducedlifespan genes in adulthood reduced the longevity of adult flies. We presumed that two possibilities might account for the observed reduction in lifespan: misexpressed reducedlifespan genes might induce ectopic cell death, leading directly or indirectly to the individual's death, or they might cause fatal organ failure. To distinguish between these two possibilities, we studied the involvement of apoptosis in the reduction in lifespan, since several genes known to induce apoptosis were identified among the reduced-lifespan genes (Table 1). For example, dream is a Caspase initiator in Drosophila, and its misexpression induces apoptosis in vivo [38]. The human slipper ortholog MLK2 is known to induce apoptosis in HN33 cells [39]. Thus, it was possible that some reduced-lifespan genes would be found to induce apoptosis. 
Table 1 Summary of reduced-lifespan genes

\begin{tabular}{|c|c|c|c|}
\hline Reduced-lifespan gene & GS number of 1st positive lines & HS/no-HS ${ }^{c}$ & $\mathrm{p} 35 / \mathrm{GFP}^{d}$ \\
\hline Transportin & $11030^{a}, 13069^{b}$ & $1.9 / 63.0(3.02 \%)$ & $3.0 / 4.1(-)$ \\
\hline Dream & $16231^{a, b}$ & $1.3 / 34.6(3.76 \%)$ & $41.6 / 1.0(+)$ \\
\hline CG10277 & $11124^{a, b}, 15951$ & $1.9 / 50.0(3.80 \%)$ & $1.0 / 2.0(-)$ \\
\hline Hepatocyte nuclear factor 4 & $10535^{a, b}$ & $1.9 / 48.6(3.91 \%)$ & $2.9 / 41.3(-)$ \\
\hline Calpain-A & $11846^{a, b}$ & $2.1 / 46.0(4.57 \%)$ & ND \\
\hline Transfer RNA:ile:49Fb & $14941^{a, b}$ & 3.0/65.1 (4.61\%) & $54.9 / 2.0(+)$ \\
\hline Combgap & $11121^{a, b}, 14406$ & $2.0 / 43.0(4.65 \%)$ & $2.0 / 3.0(-)$ \\
\hline trpy & $16894^{a, b}$ & $1.8 / 36.8(4.89 \%)$ & $1.1 / 1.0(-)$ \\
\hline Apontic & $15217^{a, b}$ & 2.2/44.8 (4.91\%) & 3.0/3.0 (-) \\
\hline Cadmus & $14710^{a, b}$ & $3.0 / 61.0(4.92 \%)$ & $2.7 / 3.8(-)$ \\
\hline PolyA-binding protein & $13841,15168^{a, b}$ & $2.4 / 46.7(5.14 \%)$ & $21.3 / 5.2(+)$ \\
\hline Embryonic lethal abnormal vision & $5211^{a, b}$ & 2.6/43.6 (5.96\%) & $21.7 / 4.1(+)$ \\
\hline CG3363 & $11052^{a, b}, 11427,13243$ & $3.0 / 49.0(6.12 \%)$ & $8.4 / 7.0(-)$ \\
\hline Stonewall & $8015^{a, b}, 16462,17037$ & $3.2 / 52.0(6.15 \%)$ & $6.8 / 21.2(-)$ \\
\hline Degringolade & $3250,15270^{a, b}$ & $3.0 / 48.6(6.17 \%)$ & $11.9 / 4.1(-)$ \\
\hline Atlastin & $7264,11283,17467^{a}$ & $2.5 / 36.0(6.94 \%)$ & $2.0 / 1.7(-)$ \\
\hline Chromator & $8043,16669^{a, b}, 17953$ & $2.0 / 27.8(7.19 \%)$ & $3.3 / 3.1(-)$ \\
\hline Slipper & $7470^{a, b}$ & $1.3 / 16.0(8.13 \%)$ & $31.9 / 1.0(+)$ \\
\hline Polo & $16634^{a, b}, 16673,20105$ & $3.9 / 44.8(8.71 \%)$ & $13.9 / 28.0(-)$ \\
\hline Without children & $10711^{a, b}$ & $2.8 / 32.0(8.75 \%)$ & $8.1 / 2.1(+)$ \\
\hline Heterogeneous nuclear ribonucleoprotein at $27 \mathrm{C}$ & $10478,11696,13072^{a, b}, 13193,14409,14755,16784,16954$ & $3.4 / 38.0(8.95 \%)$ & $22.3 / 36.5(-)$ \\
\hline High mobility group protein D & $9106,9272,9689^{b}, 10504,10665^{a}, 12910,17197$ & $2.6 / 25.0(10.40 \%)$ & $3.0 / 2.0(-)$ \\
\hline Fmr1 & $11128^{b}, 11947^{a}$ & $5.0 / 45.0(11.11 \%)$ & $11.4 / 5.4(-)$ \\
\hline Peroxin 16 & $12435^{a, b}, 14333,15386$ & $3.6 / 31.0(11.61 \%)$ & $17.4 / 22.1(-)$ \\
\hline Pipsqueak & $12449^{a, b}$ & $6.7 / 51.1(13.11 \%)$ & $9.9 / 41.1(-)$ \\
\hline CG8290 & $12665^{a, b}$ & $4.7 / 34.9(13.47 \%)$ & $34.8 / 7.8(+)$ \\
\hline Vacuolar H + ATPase subunit 100-2 & $10911^{a, b}, 14367$ & $7.1 / 50.4(14.09 \%)$ & $2.8 / 31.6(-)$ \\
\hline CG10321 & $10668^{a, b}$ & $3.9 / 27.0(14.44 \%)$ & $3.2 / 4.4(-)$ \\
\hline Roadkill & $14361,14844,15232,15233^{a, b}$ & $6.3 / 41.8(15.07 \%)$ & $3.0 / 6.6(-)$ \\
\hline Lamin & $16890^{a, b}$ & $4.5 / 28.3(15.90 \%)$ & $3.9 / 3.4(-)$ \\
\hline Elfless & $15946^{a, b}$ & $3.3 / 20.0(16.50 \%)$ & 4.0/9.0 (-) \\
\hline CG16779 & $9601^{a, b}$ & $4.4 / 26.0(16.92 \%)$ & $36.5 / 32.5(-)$ \\
\hline Elongation factor Tu mitochondrial & $11862^{a, b}$ & 8.6/42.2 (20.38\%) & $14.9 / 20.1(-)$ \\
\hline CG11819 & $5065^{a, b}$ & $6.1 / 29.0(21.03 \%)$ & $22.7 / 14.8(-)$ \\
\hline Autophagy-specific gene 1 & $15847^{a, b}$ & $12.6 / 57.8(21.80 \%)$ & $21.8 / 5.0(+)$ \\
\hline CG8032 & $5196^{a, b}$ & $2.8 / 12.1(23.14 \%)$ & $46.9 / 8.3(+)$ \\
\hline N-methyl-D-aspartate receptor-associated protein & $16440^{a, b}$ & $3.1 / 13.3(23.31 \%)$ & 2.8/17.7 (-) \\
\hline Src oncogene at $42 \mathrm{~A}$ & $11022,11049^{a, b}$ & 2.6/11.0 (23.64\%) & $4.5 / 5.4(-)$ \\
\hline CG30482 & $9799^{a, b}$ & $6.8 / 26.3(25.86 \%)$ & $5.0 / 28.5(-)$ \\
\hline Average & & $4.0 / 38.5(10.40 \%)$ & $13.5 / 11.6$ \\
\hline
\end{tabular}

${ }^{a}$ Representative GS lines used for second screen. The mean longevities are listed on the third column (HS/no-HS)

${ }^{b} \mathrm{GS}$ lines used for p35 assay.

cMean longevity (days) of heat-shocked (HS)/not-heat-shocked flies (no-HS)

${ }^{d}$ Mean longevity (days) of flies coexpressing p35 (p35)/or GFP (GFP). (+) indicates longevity extended more than three times by p35 as compared to GFP coexpression. 
Table 2 Disease-related reduced-lifespan genes

\begin{tabular}{|c|c|c|c|c|}
\hline Reduced-lifespan gene & Human ortholog & ${\text { Homology }(\%)^{a}}^{a}$ & Related diseases & Reference \\
\hline dream & CASP9 & 28 & Alzheimer's disease, Cancer & $\begin{array}{l}\text { ROHN and HEAD [23], } \\
\text { DEVARAJAN et al. [24] }\end{array}$ \\
\hline Hepatocyte nuclear factor 4 & HNF4alpha & 67 & Diabetes & OMIM *600281 \\
\hline Calpain-A & CAPN3 & 39 & Muscular dystrophy & OMIM *114240 \\
\hline embryonic lethal abnormal vision & ELAVL4 & 53 & Cancer, Anti-Hu syndrome & SZABO et al. [25] \\
\hline degringolade & RNF4 & 42 & Cancer & $\begin{array}{l}\text { HIRVONEN-SANTTI et al. [26], } \\
\text { PERO et al. [27] }\end{array}$ \\
\hline atlastin & ATL1 & 56 & Spastic paraplegia & OMIM *606439 \\
\hline slipper & $M L K 2$ & 50 & Huntington's disease & PHELAN et al. [28] \\
\hline polo & $P L K 1$ & 52 & Cancer & STREBHARDT [29] \\
\hline High mobility group protein D & SSRP1 & 52 & Cancer & HUDSON et al. [30] \\
\hline Fmr1 & FXR1 & 49 & Fragile $\mathrm{X}$ mental retardation & VERKERK et al. [31] \\
\hline Peroxin 16 & PEX16 & 36 & Zellweger syndrome & OMIM *603360 \\
\hline Vacuolar H+ ATPase subunit 100-2 & ATP6VOA4 & 51 & Distal renal tubular acidosis & OMIM *605239 \\
\hline roadkill & SPOP & 79 & Cancer & LIU et al. [32] \\
\hline CG8290 & ATRX & 36 & $\begin{array}{l}\text { ATRX (Xlinked athalassemia } \\
\text { with mental retardation) }\end{array}$ & OMIM *300032 \\
\hline Lamin & LMNA & 38 & $\begin{array}{l}\text { More than a dozen different inherited } \\
\text { diseases, including progeria syndrome }\end{array}$ & OMIM *150330 \\
\hline Elongation factor Tu mitochondrial & TUFM & 66 & $\begin{array}{l}\text { Combined oxidative } \\
\text { phosphorylation deficiency }\end{array}$ & OMIM *602389 \\
\hline CG11819 & UNC13D & 23 & $\begin{array}{l}\text { Familial hemophagocytic } \\
\text { lymphohistiocytosis-3 }\end{array}$ & OMIM *608897 \\
\hline CG8032 & SMOX & 33 & Cancer & $\begin{array}{l}\text { BABBAR and CASERO [33], } \\
\text { GOODWIN et al. [34], XU et al. [35] }\end{array}$ \\
\hline $\begin{array}{l}N \text {-methyl-D-aspartate } \\
\text { receptor-associated protein }\end{array}$ & GRINA & 46 & Epilepsy & BONAGLIA et al. [36] \\
\hline Src oncogene at $42 \mathrm{~A}$ & FRK & 61 & Cancer & HOSOYA et al. [37] \\
\hline
\end{tabular}

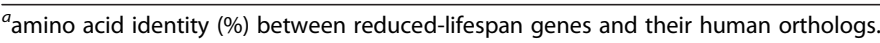

To investigate this possibility, we coexpressed $p 35$, which encodes a viral Caspase inhibitor, with each reducedlifespan gene and looked for a rescue of the reduction in adult longevity seen with misexpression of reduced-lifespan genes [40]. For this experiment, the flies carried two UAS promoters, the GS and UAS-p35 promoters. Since these promoters compete to bind GAL4 proteins, the presence of the UAS-p35 promoter attenuates the activation of the GS promoter. To evaluate the extent to which such attenuation affected longevity, we coexpressed UAS-GFP as a control with each reduced-lifespan gene. The average of the mean longevities of adult flies coexpressing UAS-GFP and a reduced-lifespan gene was 11.6 days (Table 1). However, the average of the mean longevities of adult flies misexpressing a reduced-lifespan gene alone was 4.0 days. These results suggested that the competition of the two UAS promoters for GAL4 protein binding attenuated the expression of the reduced-lifespan genes.

The effect of this attenuation differed among the reduced-lifespan genes. For 10 of the 39 reduced-lifespan genes, coexpressing UAS-GFP with the misexpressed gene more than tripled the mean longevity of the adult flies (Table 1). However, for the other 29 reduced-lifespan genes, coexpressing UAS-GFP did not significantly extend the adults' mean longevity. These results suggest that the threshold level at which the gene expression reduces the adult lifespan differs among the reduced-lifespan genes. The mean longevity of flies that misexpressed either UASp35 or UAS-GFP, but were otherwise wild-type, was 53.3 and 59.3 days, respectively (Figure $3 \mathrm{~A}$ ). Therefore, misexpressed UAS-p35 or UAS-GFP alone did not affect the longevity of adult flies.

Before examining the effect of p35 on the individual reduced-lifespan genes identified in our screen (Table 1), we performed another control experiment in which we tested whether the reduced life span induced by apoptosis could be restored by misexpressing UAS-p35. In Drosophila, the rpr gene is required for the induction of apoptosis. Ectopic rpr expression induces apoptosis in vivo [41], and $r p r$-induced apoptosis is effectively suppressed by p35 coexpression in vivo [42]. Here, we found that the misexpression of $r p r$ in adulthood severely reduced adult 

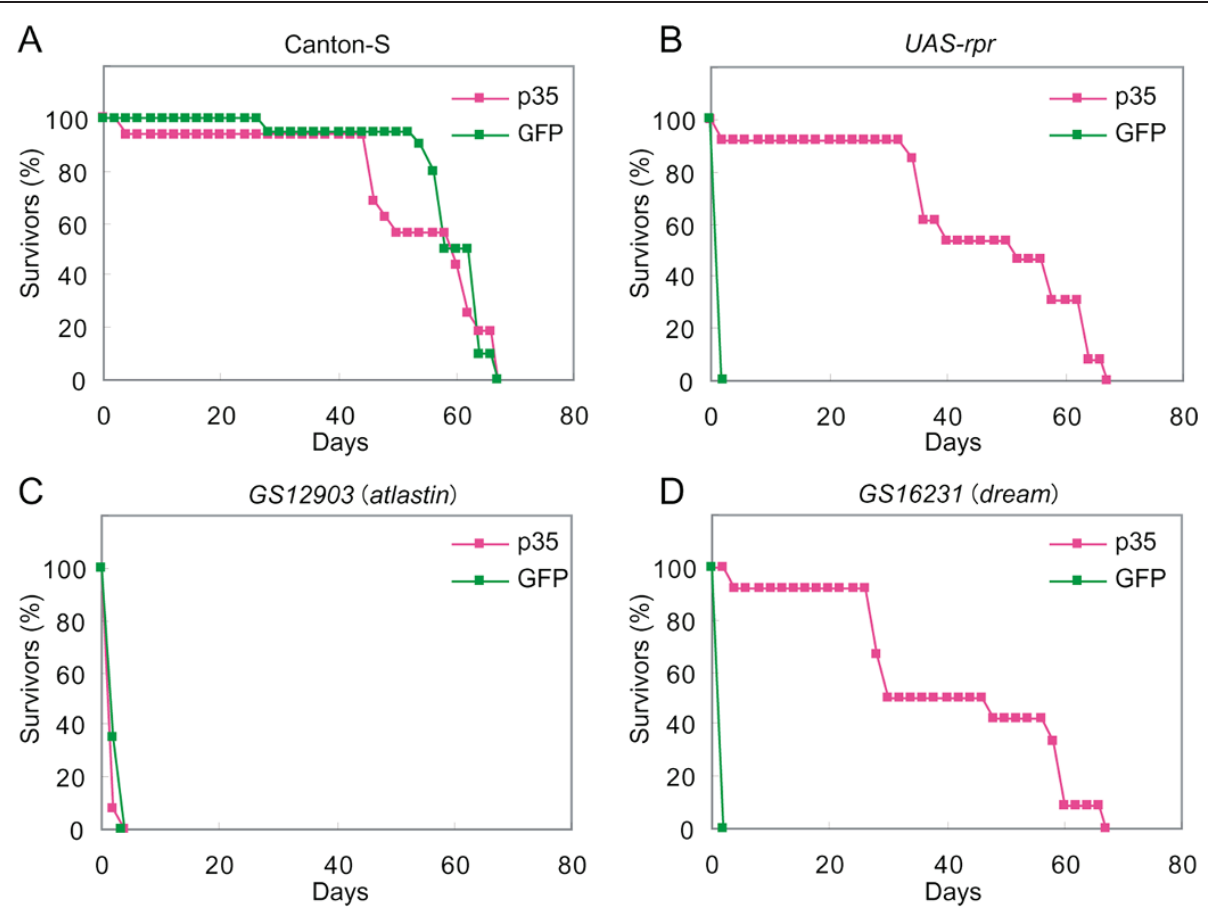

Figure 3 Inhibiting apoptosis suppressed the reduced lifespan associated with misexpressed reduced-lifespan genes. Survival curves of adult flies expressing UAS-p35 (magenta), which encodes an apoptosis inhibitor, or UAS-GFP (green). Survivor rates are shown for 2-day intervals. (A) Control (Canton-S) flies; (B-D) flies coexpressing the reduced-lifespan gene (B) UAS-rpr, (C) atlastin (misexpression driven by GS12903), or (D) dream (misexpression driven by GS16231).

longevity (to 1.3 days) (Figure 3B); this shortened longevity was significantly restored by coexpressing UAS-p35 (Figure 3B). These results suggested that p35 could effectively suppress the reduction in lifespan caused by ectopically induced apoptosis in adulthood.

We next examined how the reduction in lifespan caused by misexpressed reduced-lifespan genes in adults was affected by coexpressing UAS-p35. Each reducedlifespan gene was coexpressed with either UAS-p35 or $U A S-G F P$, driven by heat-shock, in adult flies, and the mean longevity of the two populations was measured (Table 1). We found that the longevity shortened by the misexpression of nine of the 39 reduced-lifespan genes was increased over three times in flies coexpressing UAS-p35 compared with those coexpressing UAS-GFP (Table 1), suggesting that these nine reduced-lifespan genes directly or indirectly induced apoptosis, severely shortening the adult lifespan. Survivor rates, measured every three days, were presented as survival curves of the adult flies coexpressing each reduced-lifespan gene and either UAS-p35 or UAS-GFP (Figure 3 and Additional file 3: Figure S2). As a control, UAS-rpr was coexpressed with UAS-p35 or UAS-GFP (Figure 3B). The survivor curves associated with the misexpression of these nine reducedlifespan genes shared similarities with the UAS-rpr curves. For example, as with $U A S$-rpr, the survivor curves involving dream indicated that the reduced lifespan was effectively suppressed by the coexpression of UAS-p35 but not of UAS-GFP (Figure 3D). These results suggested that apoptosis plays a critical role in the severe reduction in longevity when one of these nine genes is misexpressed in adults.

To confirm this idea, we examined the ectopic apoptosis induced by the adult-specific expression of these nine genes, using TUNEL assays [43]. In adult flies, the brain is one of the most suitable organs for observing ectopic apoptosis. For example, apoptotic neurodegeneration is labeled by TUNEL in the adult brain in a Drosophila model of neurodegenerative disease [44]. As a control, UAS-rpr misexpression in adults was driven by $h s-G A L 4$, as performed in our screens. The brain was dissected out from flies that were still alive after more than $50 \%$ of the adult flies had died, and the apoptosis in the brain was assayed by TUNEL (Additional file 4: Figure S3, B). Under these conditions, the adult-specific misexpression of dream, $A u$ tophagy-specific gene 1, and CG8032 ectopically induced apoptosis in the brain (Additional file 4: Figure S3, C-E). Based on the percentage of TUNEL-positive brains upon the adult-specific misexpression of these nine reducedlifespan genes, which probably reduce adult longevity through apoptosis, our results suggest that dream, $A u$ tophagy-specific gene 1, and CG8032 are more potent apoptosis inducers than the other six reduced-lifespan genes tested (Additional file 4: Figure S3, F). 
On the other hand, the survivor curves associated with other reduced-lifespan genes, for example, atlastin (atl), when coexpressed with either UAS-p35 or UAS-GFP were largely comparable (Figure $3 \mathrm{C}$, and Table 1 ), suggesting that the shortened longevity associated with the misexpression of this class of reduced-lifespan genes may not be accounted for by the induction of apoptosisalthough it is possible that these genes induce apoptosis that is not suppressed by $p 35$ coexpression.

\section{Tissues responsible for shortening longevity when reduced-lifespan genes are misexpressed}

In our analysis above, the effect of reduced-lifespan genes on longevity was evaluated by their misexpression in the whole body of the adult fly. To better understand how each of these genes causes reduced lifespan, it is important to determine which tissues or organs are responsible for the reduced lifespan when the gene is misexpressed. To examine this, we controlled the reduced-lifespan gene expression temporally and spatially using the TARGET system [45], which combines temperature-sensitive GAL80 $\left(\mathrm{GAL}^{\mathrm{ts}}{ }^{\mathrm{ts}}\right.$ control of GAL4 activity with a GAL4/UAS system. The Drosophila tub-GAL80 ${ }^{t s}$ line ubiquitously expresses $G A L 80^{t s}$ in vivo [45]. Tissue-specific GAL4 expression was driven by various GAL4 driver lines. In flies carrying a GAL4 driver and $t u b-G A L 80^{t s}$, the GAL4 activity is suppressed at $19^{\circ}$ and restored at $30^{\circ}$ [45].

We used eight different GAL4 driver lines to express GAL4 in specific tissues. The GAL4 expression pattern was confirmed in the adult tissues of each of these lines by crossing them with the UAS-GFP line (Table 3). To analyze the GAL4 expression patterns in the brain and gut in more detail, we stained these tissues with an antiGFP antibody. The results confirmed that these GAL4 lines showed representative differential GAL4 expression (Additional file 5: Figure S4).

To suppress the expression of reduced-lifespan genes until adulthood, flies carrying various GAL4 drivers, tub$G A L 80^{t s}$, and GS vectors were cultured at $18^{\circ}$ until eclosion. Adult flies were collected for 5 days, and 2 days

Table 3 Expression patterns of GAL4 drivers in adults

\begin{tabular}{ll}
\hline GAL4 driver & Expression pattern in adult tissues \\
\hline P\{GaWB\}(3)31-1 $31-1$ & $\begin{array}{l}\text { Brain, basiconical sensilla, } \\
\text { thoracico-abdominal ganglion, salivary glands }\end{array}$ \\
48Y-GAL4 & Brain, anterior-midgut, paragonia, salivary glands \\
$24 B-G A L 4$ & $\begin{array}{l}\text { Somatic musculature, visceral musculature, } \\
\text { salivary glands }\end{array}$ \\
NP5021 & Whole gut \\
byn-GAL4 & Hindgut \\
drm-GAL4 & Small intestine \\
Cg-GAL4 & Hemocytes \\
P\{GaWB\}5108 & Salivary glands \\
\hline
\end{tabular}

later the misexpression of reduced-lifespan genes in specific adult tissues was induced by a temperature shift from $18^{\circ}$ to $30^{\circ}$. We measured the survivor rate every three days and calculated the mean longevity (Table 4 ). In these experiments, longevity was measured in flies maintained at $30^{\circ}$, which generally have a shorter lifespan than those cultured at $25^{\circ}$ (Table 1; Table 4). Therefore, we compared their longevity with that of otherwise wild-type flies expressing GAL4 (Canton-S in Table 4) at $30^{\circ}$. We successfully identified reduced-lifespan genes that, when expressed in specific tissues, reduced the mean longevity to less than one-third of that in control flies (Table 4 and magenta in Figure 4).

Of the 39 reduced-lifespan genes identified in our screens, we found 24 that reduced the adult longevity when their misexpression was driven by one or more GAL4 drivers specifically in adulthood. Among these, 15 genes shortened longevity only when their misexpression was driven by one particular GAL4 driver (Figure 4A, and Additional file 6: Figure S5). On the other hand, nine reduced-lifespan genes severely reduced the adult longevity when misexpressed by at least two different GAL4 drivers (Table 4). For example, High mobility group protein $D$ severely shortened longevity when its misexpression was driven by several GAL4 lines (Table 4, Figure 4B, and Additional file 6: Figure S5). However, it remains unknown whether each of these reduced-lifespan genes induced shortened longevity in two different tissues by distinct underlying mechanisms.

Susceptibility to the misexpression of reduced lifespan differed among tissues. Many reduced-lifespan genes induced shortened longevity when misexpressed under the GAL4 drivers 24B-GAL4 or NP5021, but not under other GAL4 drivers (Table 4). Of the 39 reduced-lifespan genes, the misexpression of 11 shortened the lifespan when driven by $24 B-G A L 4$ (brain, visceral muscle, and Malpighian tubules) and 14 when driven by NP5021 (gut epithelium and Malpighian tubules) (Table 4, Figure 4C, and data not shown). These results suggest that the gut and Malpighian tubules are more susceptible to many misexpressed reduced-lifespan genes. Unexpectedly, when the misexpression was driven by $48 Y-G A L 4$ or $P\{G a w B\} l(3)$ $31-1^{31-1}$, which highly express GAL4 in the brain (medium and strong levels in (Additional file 5: Figure S4), only two or three of the 39 reduced-lifespan genes severely reduced adult longevity (Table 4 and Figure 4D), suggesting that neuronal cells may have some tolerance to perturbation by misexpressed genes. In contrast, while the neuronspecific misexpression of dream driven by $48 Y$-GAL4 did not reduce longevity, its misexpression in the gut epithelium and Malpighian tubules severely reduced it, as mentioned above (Table 4). Since the reduction in longevity by dream misexpression was effectively restored by coexpressing $p 35$, apoptosis in neuronal cells may not strongly influence adult longevity. 
Table 4 Mean longevity of adult flies with the misexpression of reduced-lifespan genes in specific adult tissues

\begin{tabular}{|c|c|c|c|c|c|c|c|c|c|}
\hline \multirow[t]{2}{*}{ Reduced-lifespan gene } & \multirow{2}{*}{$\begin{array}{c}\text { GS } \\
\text { line. no. }\end{array}$} & \multicolumn{8}{|c|}{ GAL4 driver line } \\
\hline & & $P\{$ GawB $\} \mid(3) 31-1^{31-1}$ & $48 Y-G A L 4$ & $24 B-G A L 4$ & NP5021 & byn-GAL4 & $d r m-G A L 4$ & $C g-G A L 4$ & $P\{G a w B\} 5108$ \\
\hline Transportin & 11030 & 33.4 & 33.5 & 32.7 & 15.6 & 39.8 & 33.5 & 25.6 & 33.0 \\
\hline Dream & 16231 & 29.1 & 34.7 & 3.0 & 4.6 & 21.8 & 25.2 & 30.9 & $(30.0)$ \\
\hline CG10277 & 11124 & 35.4 & 32.5 & 23.4 & 7.6 & 25.1 & 27.9 & 27.9 & 32.1 \\
\hline $\begin{array}{l}\text { Hepatocyte nuclear } \\
\text { factor } 4\end{array}$ & 10535 & 37.8 & 29.1 & 27.7 & 13.8 & 25.3 & 30.2 & 31.6 & 35.5 \\
\hline Calpain-A & 9176 & 30.0 & $(37.8)$ & 23.5 & 17.8 & $(19.5)$ & 21.3 & 23.5 & 29.4 \\
\hline Transfer RNA:ile:49Fb & 14941 & 33.3 & $(19.2)$ & 33.7 & 4.1 & 28.8 & 31.2 & 29.0 & 36.8 \\
\hline Combgap & 11121 & 27.6 & 28.8 & 5.5 & 20.1 & 7.8 & 20.5 & 30.7 & $(28.8)$ \\
\hline trpy & 16894 & 33.2 & 31.0 & 31.0 & 19.2 & 30.8 & 27.0 & 35.3 & $(31.2)$ \\
\hline Apontic & 15217 & 9.4 & 27.9 & 36.3 & 7.8 & 34.4 & 29.1 & 31.7 & 25.5 \\
\hline Cadmus & 14710 & 33.3 & 35.3 & 38.2 & 26.7 & 36.9 & 21.0 & 26.6 & 34.3 \\
\hline PolyA-binding protein & 15168 & 33.0 & 32.1 & 9.3 & 5.3 & 23.2 & 29.8 & 26.3 & 35.1 \\
\hline $\begin{array}{l}\text { Embryonic lethal } \\
\text { abnormal vision }\end{array}$ & 5211 & 27.7 & 31.1 & 6.0 & 30.0 & 12.2 & 33.0 & 26.6 & 31.5 \\
\hline CG3363 & 11052 & 20.7 & 18.5 & 8.8 & 11.6 & 22.4 & 19.5 & 21.0 & 33.9 \\
\hline Stonewall & 8015 & 24.8 & 33.4 & 12.6 & 10.2 & 18.7 & 32.6 & 17.1 & 36.0 \\
\hline Degringolade & 15270 & 22.6 & 33.3 & 20.1 & 9.2 & 17.0 & 11.6 & 29.7 & 36.5 \\
\hline Atlastin & 17467 & 8.5 & 35.1 & 27.3 & 16.2 & 17.3 & 31.7 & 30.2 & 42.2 \\
\hline Chromator & 16669 & 25.5 & 17.1 & 5.3 & 13.1 & 9.6 & 9.6 & 14.6 & $(27.0)$ \\
\hline Slipper & 7470 & 13.1 & 14.8 & 7.3 & 26.8 & 21.9 & 25.5 & 8.1 & 26.7 \\
\hline Polo & 16634 & 30.9 & 13.6 & 29.6 & 24.3 & 24.9 & 35.1 & 28.8 & 35.6 \\
\hline Without children & 10711 & 27.3 & 38.1 & 16.3 & 8.1 & 22.3 & 26.3 & 16.7 & 29.0 \\
\hline $\begin{array}{l}\text { Heterogeneous nuclear } \\
\text { ribonucleoprotein at } 27 \mathrm{C}\end{array}$ & 13072 & 18.5 & 13.8 & 6.0 & 13.8 & 5.1 & 15.6 & 25.8 & 33.5 \\
\hline $\begin{array}{l}\text { High mobility group } \\
\text { protein D }\end{array}$ & 10665 & 10.4 & 6.9 & 3.0 & 6.0 & 5.4 & 21.6 & 23.4 & 29.2 \\
\hline Fmr1 & 11947 & 30.0 & 21.4 & 5.8 & 14.8 & 15.0 & 23.7 & 14.5 & (36.6) \\
\hline Peroxin 16 & 12435 & 34.3 & 32.0 & 24.0 & 12.8 & 32.4 & 18.6 & 31.7 & $(21.6)$ \\
\hline Pipsqueak & 12449 & 27.3 & 30.4 & 7.7 & 6.0 & 25.4 & 30.5 & 29.4 & 29.0 \\
\hline CG8290 & 12665 & 32.1 & 21.7 & 19.2 & 26.4 & 16.4 & 33.6 & 32.4 & 37.0 \\
\hline $\begin{array}{l}\text { Vacuolar } H+\text { ATPase } \\
\text { subunit 100-2 }\end{array}$ & 10911 & 35.8 & (35.4) & 34.2 & 26.4 & 24.4 & 29.1 & 35.3 & $(37.2)$ \\
\hline CG10321 & 10668 & 24.6 & 35.0 & 12.0 & 10.5 & 13.4 & 35.3 & 19.3 & 32.8 \\
\hline Roadkill & 15233 & 32.9 & 38.5 & 27.9 & 31.1 & 34.1 & 32.8 & 31.4 & (35.3) \\
\hline Lamin & 16890 & 21.5 & 22.5 & 21.6 & 6.0 & 12.2 & 17.8 & 10.9 & 23.9 \\
\hline Elfless & 15946 & 30.6 & 28.4 & 22.8 & 20.6 & 20.6 & 31.4 & 29.9 & 34.4 \\
\hline CG16779 & 9601 & 26.9 & 34.5 & 11.7 & 16.5 & 31.2 & 34.5 & 18.0 & 45.0 \\
\hline $\begin{array}{l}\text { Elongation factor Tu } \\
\text { mitochondrial }\end{array}$ & 11862 & 29.0 & 28.3 & 23.3 & 22.8 & 31.5 & 15.5 & 31.3 & $(27.6)$ \\
\hline CG11819 & 5065 & 31.1 & 35.0 & 31.5 & 7.5 & 28.1 & 30.2 & 32.1 & 34.7 \\
\hline Autophagy-specific gene 1 & 15847 & 29.5 & 34.2 & 32.6 & 14.7 & 28.1 & 27.2 & 31.7 & 37.8 \\
\hline CG8032 & 5196 & 38.4 & 28.4 & 33.9 & 12.6 & 30.0 & 35.1 & 28.8 & 32.0 \\
\hline
\end{tabular}


Table 4 Mean longevity of adult flies with the misexpression of reduced-lifespan genes in specific adult tissues (Continued)

\begin{tabular}{|c|c|c|c|c|c|c|c|c|c|}
\hline $\begin{array}{l}N \text {-methyl-D-aspartate } \\
\text { receptor-associated protein }\end{array}$ & 16440 & 27.6 & 5.5 & 15.4 & 15.8 & 20.6 & 16.7 & 23.9 & 31.5 \\
\hline Src oncogene at $42 \mathrm{~A}$ & 11049 & 21.6 & 21.9 & 17.1 & 9.8 & 19.2 & 24.6 & 16.1 & 33.0 \\
\hline Canton-S (control) & & 37.6 & 32.9 & 34.9 & 31.5 & 31.8 & 35.7 & 28.4 & 34.4 \\
\hline
\end{tabular}

Bold numbers indicate longevity less than 1/3 of control. Parenthetical numbers indicate the mean longevity obtained from fewer than five flies.

Classification of reduced-lifespan genes by gene ontology To explore common biological functions among the reduced-lifespan genes, we conducted gene ontology (GO) analysis. Gene ontology provides annotations for each gene along with insights into the biology of the system being studied [46]. We focused on biological process, which is one of three main GO categories. This category contains 30490 GO terms. One or more GO term was found for 10535 Drosophila melanogaster genes. We found that 33 of the 39 reduced-lifespan genes had at least one GO term. We then searched for significantly shared GO terms associated with selected genes. The p-value was calculated by a one-tailed
Fisher's exact test ( $p$-value $<0.001)$. We filtered the GO terms containing more than 10 reduced-lifespan genes. Significant shared terms are shown in Table 5. The GO term "developmental process" had the lowest p-value of all the terms. In addition, five out of seven terms were related to development. These results indicate a bias of reducedlifespan genes toward development-related genes.

Among the 39 reduced-lifespan genes, we found that human orthologs of six genes-embryonic lethal abnormal vision, Heterogeneous nuclear ribonucleoprotein at 27C, Vacuolar $\mathrm{H}^{+}$ATPase subunit 100-2, Elongation factor Tu mitochondrial, High mobility group protein $D$, and polyA-
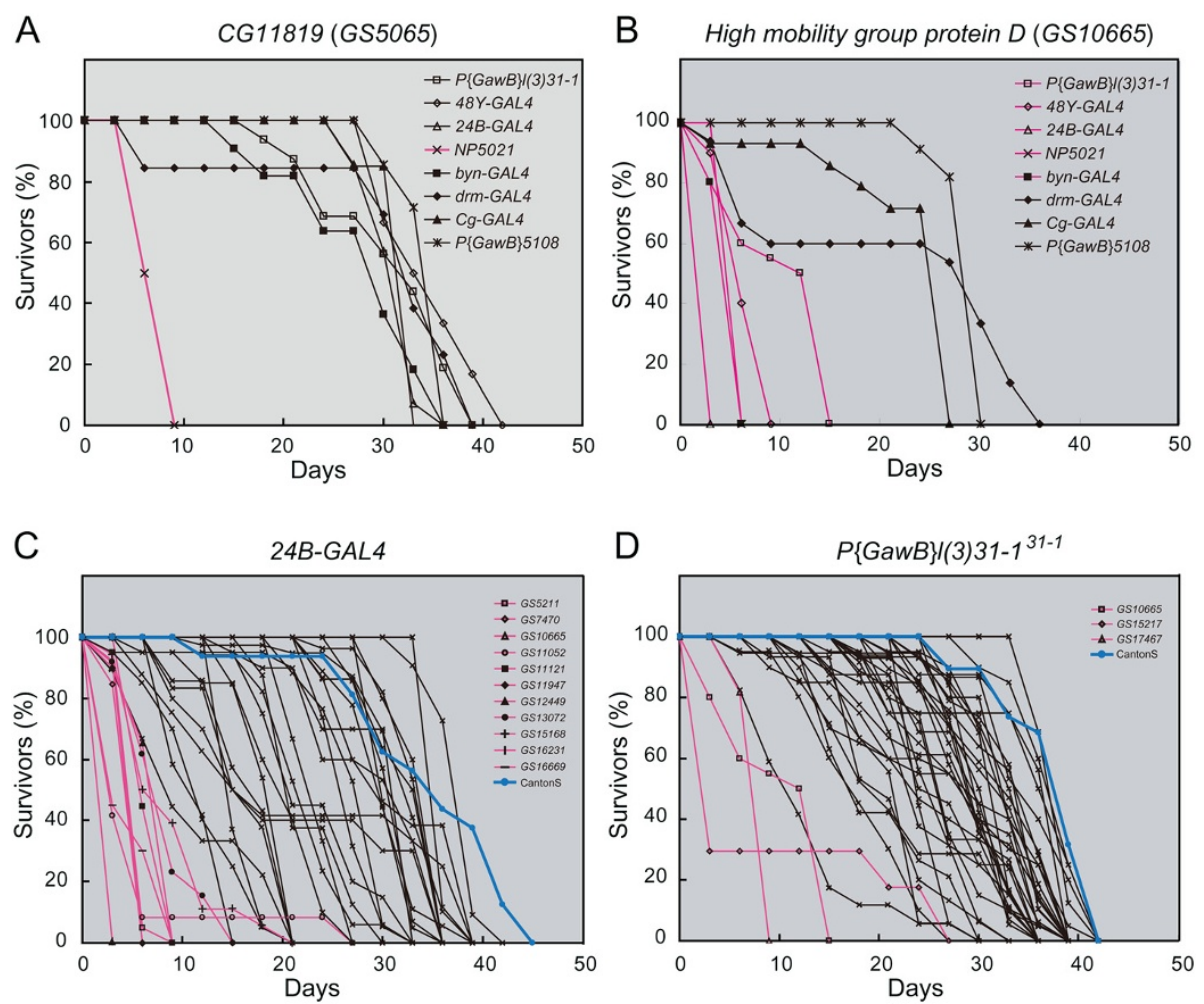

Figure 4 Misexpression of reduced-lifespan genes in specific tissues was responsible for reduced lifespan in adult flies. Misexpression of reduced-lifespan genes in specific tissues was responsible for reduced lifespan in adult flies. (A-D) Survival curves of adult flies misexpressing reducedlifespan genes. Tissue-specific expression of reduced-lifespan genes in adult flies was induced with the TARGET system. Survivor rates were scored every three days. (A, B) Two representative reduced-lifespan genes (A) GS5065 (CG11819) and (B) GS10665 (High mobility group protein D) were misexpressed using various GAL4 drivers, indicated in the upper right. (C, D) Survival curves for all identified reduced-lifespan genes when driven by the GAL4 driver (C) 24B-GAL4 or (D) P\{GawB\}/(3)31-1 ${ }^{31-1}$. Blue lines: survival curve of a wild-type (Canton-S) control. Magenta lines: survival curves showing a lifespan less than $1 / 3$ that of wild-type control flies; the corresponding reduced-lifespan genes are shown in the upper right. Survival curves showing a lifespan greater than 1/3 of that of wild-type control flies are shown in black; the corresponding gene names are not shown. 
Table 5 Significant shared GO terms between reduced-lifespan genes and total genes

\begin{tabular}{|c|c|c|c|c|c|c|c|}
\hline GO ID & GO ACCESSION & GO Term & $\mathrm{p}$-value & $\begin{array}{l}\text { Count in reduced- } \\
\text { lifespan genes }\end{array}$ & $\begin{array}{l}\% \text { Count in reduced- } \\
\text { lifespan genes }\end{array}$ & $\begin{array}{l}\text { Count in } \\
\text { total genes }\end{array}$ & $\begin{array}{l}\% \text { Count in } \\
\text { total genes }\end{array}$ \\
\hline 14320 & GO:0032502 & Developmental process & 3.81E-05 & 16 & 48.5 & 1830 & 17.4 \\
\hline 4795 & GO:0007275 & Multicellular organismal development & $1.78 \mathrm{E}-04$ & 14 & 42.4 & 1620 & 15.4 \\
\hline 22125 & GO:0048513 & Organ development & 3.56E-04 & 10 & 30.3 & 921 & 8.7 \\
\hline 22457 & GO:0048856 & Anatomical structure development & 5.87E-04 & 12 & 36.4 & 1375 & 13.1 \\
\hline 6464 & GO:0009653 & Anatomical structure morphogenesis & $6.05 \mathrm{E}-04$ & 10 & 30.3 & 984 & 9.3 \\
\hline 22337 & GO:0048731 & System development & $6.12 \mathrm{E}-04$ & 11 & 33.3 & 1178 & 11.2 \\
\hline 14319 & $\begin{array}{l}\text { GO:0032501| } \\
\text { GO:0050874 }\end{array}$ & Multicellular organismal process & 7.14E-04 & 15 & 45.5 & 2080 & 19.7 \\
\hline
\end{tabular}

binding protein-are known as housekeeping genes [47]. These results suggested that the overproduction of proteins encoded by some housekeeping genes could affect cell physiology, which could directly or indirectly shorten longevity.

On the other hand, only four reduced-lifespan genes had an apoptosis-related GO term. The reduced-lifespan phenotype induced by the adult-specific expression of three of these, dream, polyA-binding protein, and Autophagy-specific gene 1, was suppressed by coexpressing UAS-p35 (Figure 3 and Table 1), suggesting that apoptosis was a potential cause of the reduced longevity. Thus, for these three reducedlifespan genes, the GO analysis results were consistent with our observations using UAS-p35. However, UAS-p35 coexpression suppressed the reduced-lifespan phenotype for six other reduced-lifespan genes (Table 1) that did not have an apoptosis-related GO. Therefore, we speculated that these six reduced-lifespan genes indirectly induce apoptosis by disrupting other physiological processes.

\section{Conclusions}

In this study, we identified 39 genes that induced reduced lifespan in flies when misexpressed in adulthood. In our screen, we did not study GS lines that were lethal during embryonic, larval, and/or pupal stages due to leaky gene expression driven by GS insertion. We speculate that these genes may affect cell specification or pattern formation during development, although some may strongly influence cell physiology and function at various stages of the Drosophila life cycle. Our results suggest that ectopic apoptosis and/or organ malfunction are responsible for the reduced lifespan induced by the misexpression of reduced-lifespan genes in adulthood. Based on the differences in sensitivity to apoptosis inhibition and in the tissues responsible for shortened life, the causes of reduced lifespan differ among the reduced-lifespan genes.

\section{Methods}

\section{Drosophila strains}

Canton-S was used as a wild-type strain. Flies were raised at $25^{\circ}$ unless otherwise specified. The Gene Search (GS) collection was obtained from the Drosophila Gene Search
Project [16]. The UAS lines UAS-p35, UAS-reaper (rpr), and $U A S-G F P$ were obtained from the Bloomington Stock Center. The following GAL4 drivers were used: $P\{G A L 4-$ Hsp70.PB\} (Bloomington Stock Center \#2077), P\{GawB\}l (3)31-1 $1^{31-1}$ (Bloomington Stock Center \#5820), 48Y-GAL4 [48], 24B-GAL4 [49], drumstick (drm)-GAL4 [50], Cg-GAL4 (Bloomington Stock Center \#7011), brachyenteron (byn)GAL4 [51], NP5021 [52], and P\{GawB\}5108 (Bloomington Stock Center \#2736); tub-GAL80 ${ }^{t s}$ was also obtained from the Bloomington Stock Center (\#7016 and \#7017).

\section{Genetic screening}

GS lines express arbitrary genes downstream of the upstream activation sequence (UAS), depending on the insertion locus of each GS vector [16]. To overexpress these genes specifically in adult flies, we used a heat-inducible GAL4 driver, $P\{G A L 4-H s p 70 . P B\}$, referred to as heat-shockGAL4 (hs-GAL4) [17]. Figure 1A shows the scheme of genetic crosses performed for this screen. GS flies carrying GS vectors inserted on the 2nd or 3rd chromosome were crossed with virgin $h s-G A L 4$ females. For GS lines with a GS vector on the $\mathrm{X}$ chromosome, virgin females were collected and crossed with $h s$-GAL4 males. To suppress potential leaky $h s-G A L 4$ expression during development, flies were crossed and the offspring (F1) raised at $18^{\circ}$.

For the primary screen, in most cases 10 to $20 \mathrm{~F} 1$ males were collected for 5 days starting from the first day of eclosion, and were kept at $18^{\circ}$ for two days. These F1 flies ( 2 to 7 days old) were heat-shocked at $37^{\circ}$ for $20 \mathrm{~min}$, and then maintained at $25^{\circ}$. Dead flies were counted 5 days after the heat-shock treatment, and lethality was defined as the percentage of all heat-shocked flies that were dead flies.

For the second screen, in most cases 20 to $40 \mathrm{~F} 1$ flies from the potentially positive GS lines, obtained as described for the primary screen, were divided into equal groups. One group was heat-shocked at $25^{\circ}$ for $20 \mathrm{~min}$ and the other was not heat-shocked; lethality was measured for each group as described for the primary screen. GS vector insertion sites, if not already reported, were determined by genomic PCR as described by the Drosophila Gene Search Project [16]. 


\section{Semi-quantitative RT-PCR}

Arbitrarily selected GS lines capable of driving reducedlifespan genes were crossed with hs-GAL4, and the F1 flies were cultured by the same method used in the secondary screen. Three adult flies for each experiment were heat-shocked $\left(37^{\circ}\right)$ or non-heat-shocked $\left(18^{\circ}\right)$ for $20 \mathrm{~min}$ and subsequently maintained for 6 hours at $25^{\circ}$. From these flies, the total RNA was extracted using Isogen (Nippon Gene), and treated with RNase-free DNase (Takara). Semi-quantitative RT-PCR was performed as described before [53]. First-strand cDNA was synthesized using the $1^{\text {st }}$ strand cDNA Synthesis Kit (Takara), and PCR was performed using ExTaq (Takara). The following oligonucleotides were used as PCR primers: Transportin, 5'-GAGGAGACCAAGCAGTACATACG-3' and 5' '-TTCAACTGGGCACACATAACC-3'; CG10277, 5'-G ACACCTGTGTGATCTGTCTGG-3' and 5'-GCCCTTC GTAAAAACCTTGC -3'; Calpain- $A$, 5'-GGTTCCCTT TTCGAAGATCC-3' and 5'-GAACATCAAAACGCGA ATAACC-3'; combgap, 5'-TCAAGCACCATTTGACAA CC-3' and 5'-GCACTCCTGGCACTGATAAGG-3'; polyA-binding protein, 5'-GCTGTCCATTCGTGTCT GC-3' and 5' -CGACGAAGAGAAGGATCACG-3'; CG 3363, 5' -CTCCCAAATGCCTTTTACCC-3' and $5^{\prime}$-CT CGCGCTTCAAATTATTGC-3'; stonewall, 5' -CAGAC TGCGCTTTATGATCG-3' and 5' -CCAGCGGGTATA GTCATTTCG-3'; polo, 5'-ACATCAACCAGCGGAA AACC-3' and 5'-TGTTTGATCATCAGCTTCTTGG-3'; Glyceraldehyde 3 phosphate dehydrogenase 1 (Gapdh1), 5'-GGAGCCACCTATGACGAAATCAA-3' and5'- GAC GAATGGGTGTCGCTGAA-3'. The PCR products were analyzed by $1 \%$ agarose gel electrophoresis. Gapdh1 was used an internal control for semi-quantification.

\section{Apoptosis inhibition by coexpressing $p 35$ with reduced-lifespan genes}

The baculoviral protein p35 efficiently inhibits the apoptosis signaling cascade by competing with Caspase substrates [54]. GS lines were crossed with UAS-p35; hs-GAL4 and UAS-GFP; $h s-G A L 4$. We collected 10 to $20 \mathrm{~F} 1$ flies carrying a GS vector, $h s-G A L 4$, and UAS-p35 or UASGFP. The flies were heat-shocked as described above and reared at $25^{\circ}$. Dead flies were counted every two days. UAS-rpr was used for a positive control.

\section{TUNEL assay}

Adult brains were dissected and fixed (4\% paraformaldehyde in PBS) for $30 \mathrm{~min}$ at room temperature. The brains were washed with PBS, and the endogenous peroxidase activity was blocked by incubating the samples with $0.3 \%$ $\mathrm{H}_{2} \mathrm{O}_{2}$ in methanol for $30 \mathrm{~min}$ at room temperature. The brains were washed twice in PBS, once in $0.1 \%$ Triton X$100 / 0.1 \%$ sodium citrate for $20 \mathrm{~min}$ on ice, and then twice in PBS. The TUNEL assay was performed according to the manufacturer's instructions (In Situ Cell Death Detection Kit, Roche). Fluorescent images were obtained by confocal microscopy, LSM700 (Carl Zeiss).

\section{Tissue-specific expression of reduced-lifespan genes in adulthood}

The temporal and regional gene expression targeting (TARGET) system was used to express genes in specific tissues in adult flies [45]. The following GAL4 drivers were used: $P$ $\left\{\right.$ GawB\}l(3)31-1 $1^{31-1}, 48 Y-G A L 4,24 B-G A L 4, N P 5021$, bynGAL4, drm-GAL4, Cg-GAL4, and P\{GawB\}5108. GAL4 expression in adult tissues was examined by crossing these GAL4 lines with UAS-GFP; the expression patterns are summarized in Table 3. GAL80 ${ }^{\text {ts }}$, which suppresses GAL4 at $18^{\circ}$ but not at $30^{\circ}$ [45], was expressed from tub-GAL8O $0^{t s}$ on the X chromosome (\#7016) and the third chromosome (\#7017). Flies carrying a GAL4 driver and tub-GAL80 $0^{t s}$ were crossed with GS lines with GAL4-controlled expression of reduced-lifespan genes, and the F1 progeny of these crosses were raised at $18^{\circ}$ to suppress gene expression regulated by the GS vector. Typically, 10 to $20 \mathrm{~F} 1$ males were collected within 5 days after eclosion and incubated for 2 more days at $18^{\circ}$. These adult flies were then cultured at $30^{\circ}$ to drive the expression of reduced-lifespan genes in tissues expressing GAL4. Dead flies were counted every 3 days, and mean longevities calculated as described above. Canton-S (wild-type) flies were used as a negative control.

\section{Analysis of tissue-specific GAL4 expression driven by vari- ous GAL4 lines}

To analyze the tissue-specific expression of GAL4 in various GAL4 lines used in this study, GAL4 lines (indicated at the left in Additional file 5: Figure S4) were mated with UAS-GFP. The F1 adults were cultured at $25^{\circ}$. The brain and digestive organs were dissected out, fixed with $4 \%$ paraformaldehyde in PBS, and stained with an anti-GFP antibody (1:500 dilution, Invitrogen Life Technologies) and Alexa-Fluor secondary antibody (1:200 dilution, Invitrogen Life Technologies). The GFP expression was observed by confocal microscopy, LSM700 (Carl Zeiss).

\section{Gene ontology analysis}

We used Genespring GX version 10.0 to perform gene ontology analyses and to extract the enriched gene ontology terms among the genes shortening longevity. The Pvalue of each enriched gene ontology term was obtained by a one-tailed Fisher's exact test.

\section{Additional files}

Additional file 1: Table S1. All GS lines positive for the secondary screen. Additional file 2: Figure S1. Semi-quantitative RT-PCR confirmed the misexpression of reduced-lifespan genes upon heat-shock treatment. Results of semi-quantitative RT-PCR detecting CDNA fragments of 
Transportin, CG10277, Calpain-A, combgap, polyA-binding protein, CG3363, stonewall, and polo are shown. Total RNA was isolated from adult flies carrying hs-GAL4 and a GS insertion that were subjected to the same culture conditions used in our secondary screen, with or without heat-shock treatment. The numbers 21, 24, 27, and 30 are PCR cycles. Heat shock markedly increased the RT-PCR products from Transportin, CG10277, combgap, CG3363, polo, and stonewall. Glyceraldehyde 3 phosphate dehydrogenase (Gapdh1) was used as an internal control. polo gave an additional RT-PCR product (shown by an asterisk).

Additional file 3: Figure S2. Survival curves of adult flies expressing UAS-p35 (magenta), which encodes an apoptosis inhibitor, or UAS-GFP (green), in combination with each reduced-lifespan gene (shown at the top of each graph). Details are described in Figure 3.

Additional file 4: Figure S3. The adult-specific misexpression of reduced-lifespan genes induced apoptosis in the adult brain. Canton-S (wild-type), UAS-rpr, and positive GS lines were crossed with hs-GAL4, and the F1 flies were heat-shocked as in the primary and secondary screens. Brains were dissected from flies that were still alive after more than half of the heat-shocked flies had died, and apoptotic cells were detected by TUNEL assay. Fluorescence microscopy images of adult brains are shown. Canton-S (A) and UAS-rpr (B) were used as negative and positive controls, respectively. (C-E) Representative samples of positive GS lines, GS16231 (dream) (C), GS15847 (Autophagy-specific gene 1) (D), and GS5196 (CG8032) (E), are shown. White arrowheads indicate TUNEL-positive apoptotic cells. (F) Frequency of TUNEL-positive brains is shown as a percentage. The number of samples tested is shown above each bar.

Additional file 5: Figure S4. Tissue-specific expression of GAL4 in the adult brain, gut, and Malpighian tubule in various GAL4 lines. We analyzed the GAL4 expression patterns in six lines (indicated at left). The UAS-GFP expression driven by each GAL4 line was analyzed by confocal microscopy after immunostaining for the GFP protein (green) in the adult brain and in the gut /Malpighian tubule. Corresponding optical microscopy images are shown at right. Arrows indicate visceral muscles; arrowheads show the Malpighian tubule. The regions outlined by white broken lines are magnified in panels to the immediate right. The relative intensity of GFP expression in various GAL4 lines is indicated in the bottom table, as - (negative), +/- (almost negligible), + (weak), ++ (medium), and +++ (strong).

Additional file 6: Figure S5. Tissue-specific expression experiments. Survival curves of adult flies misexpressing each reduced-lifespan gene. Tissue-specific expression was induced in adult flies with the TARGET system, and sunvivor rates were scored every three days. Details are described in Figure 4.

\section{Competing interests}

The authors declare that they have no competing interests.

\section{Authors' contributions}

$M N$, TA, YM, ST, and KM, designed the experiments. MN, TI, HS, TU, TO, HY, $H I, Y T, A M, K K, M T, J K, M A, A T, T S$, and TY conducted the experiments. MN, $\mathrm{HOI}, \mathrm{WG}$, and $\mathrm{MO}$ analyzed and interpreted the data. $\mathrm{MN}, \mathrm{HOl}$, and $\mathrm{KM}$ drafted the manuscript. All authors read and approved the final manuscript.

\section{Acknowledgements}

We thank the Bloomington Stock Center and the Drosophila Genetic Resource Center, Kyoto Institute of Technology, for fly stocks. This study was supported by the Academic Frontier Project from the Ministry of Education, Culture, Sports, Science and Technology. We are grateful to all members of the Matsuno laboratory for helpful discussion.

\section{Author details}

'Genome and Drug Research Center, Tokyo University of Science, Noda, Chiba 278-8510, Japan. ${ }^{2}$ Department of Biological Sciences, Osaka University, 1-1 Machikaneyama, Toyonaka, Osaka 560-0043, Japan. ${ }^{3}$ Department of Biological Science and Technology, Tokyo University of Science, Noda, Chiba 278-8510, Japan. ${ }^{4}$ Department of Biological Sciences, Tokyo Metropolitan University, Hachioji, Tokyo 192-0397, Japan. ${ }^{5}$ Department of Molecular Biosciences, Faculty of Life Sciences, Kyoto Sangyo University, Kita-ku, Kyoto 603-8555, Japan. ${ }^{6}$ Graduate School of Science, Chiba University, Chiba, Chiba 263-8522, Japan.
Received: 1 July 2013 Accepted: 8 April 2014

Published: 16 April 2014

\section{References}

1. Benz CC, Yau C: Ageing, oxidative stress and cancer: paradigms in parallax. Nat Rev Cancer 2008, 8(11):875-879.

2. Polidori MC: Oxidative stress and risk factors for Alzheimer's disease: clues to prevention and therapy. J Alzheimers Dis 2004, 6(2):185-191.

3. von Figura G, Hartmann D, Song Z, Rudolph KL: Role of telomere dysfunction in aging and its detection by biomarkers. J Mol Med 2009, 87(12):1165-1171.

4. Mouatt-Prigent A, Karlsson JO, Agid Y, Hirsch EC: Increased M-calpain expression in the mesencephalon of patients with Parkinson's disease but not in other neurodegenerative disorders involving the mesencephalon: a role in nerve cell death? Neuroscience 1996, 73(4):979-987.

5. Ray SK, Wilford GG, Crosby CV, Hogan EL, Banik NL: Diverse stimuli induce calpain overexpression and apoptosis in C6 glioma cells. Brain Res 1999, 829(1-2):18-27.

6. Saito K, Elce JS, Hamos JE, Nixon RA: Widespread activation of calciumactivated neutral proteinase (calpain) in the brain in Alzheimer disease: a potential molecular basis for neuronal degeneration. Proc Natl Acad Sci U S A 1993, 90(7):2628-2632.

7. Prolla TA: DNA microarray analysis of the aging brain. Chem Senses 2002, 27(3):299-306.

8. Zou S, Meadows S, Sharp L, Jan LY, Jan YN: Genome-wide study of aging and oxidative stress response in Drosophila melanogaster. Proc Natl Acad Sci U S A 2000, 97(25):13726-13731.

9. Adams MD, Celniker SE, Holt RA, Evans CA, Gocayne JD, Amanatides PG, Scherer SE, Li PW, Hoskins RA, Galle RF, George RA, Lewis SE, Richards S, Ashburner M, Henderson SN, Sutton GG, Wortman JR, Yandell MD, Zhang Q Chen LX, Brandon RC, Rogers YH, Blazej RG, Champe M, Pfeiffer BD, Wan KH, Doyle C, Baxter EG, Helt G, Nelson CR, et al: The genome sequence of Drosophila melanogaster. Science 2000, 287(5461):2185-2195.

10. Rubin GM, Yandell MD, Wortman JR, Gabor Miklos GL, Nelson CR, Hariharan IK, Fortini ME, Li PW, Apweiler R, Fleischmann W, Cherry JM, Henikoff S, Skupski MP, Misra S, Ashburner M, Birney E, Boguski MS, Brody T, Brokstein P, Celniker SE, Chenvitz SA, Coates D, Cravchik A, Gabrielian A, Galle RF, Gelbart WM, George RA, Goldstein LS, Gong F, Guan P, et al: Comparative genomics of the eukaryotes. Science 2000, 287(5461):2204-2215.

11. Min KT, Benzer S: Preventing neurodegeneration in the Drosophila mutant bubblegum. Science 1999, 284(5422):1985-1988.

12. Fortini ME, Bonini NM: Modeling human neurodegenerative diseases in Drosophila: on a wing and a prayer. Trends Genet 2000, 16(4):161-167.

13. Lu B, Vogel H: Drosophila models of neurodegenerative diseases. Annu Rev Pathol 2009, 4:315-342.

14. lijima K, lijima-Ando K: Drosophila models of Alzheimer's amyloidosis: the challenge of dissecting the complex mechanisms of toxicity of amyloidbeta 42. J Alzheimers Dis 2008, 15(4):523-540.

15. Botella JA, Bayersdorfer F, Gmeiner F, Schneuwly S: Modelling Parkinson's disease in Drosophila. Neuromolecular Med 2009, 11(4):268-280.

16. Toba G, Ohsako T, Miyata N, Ohtsuka T, Seong KH, Aigaki T: The gene search system. A method for efficient detection and rapid molecular identification of genes in Drosophila melanogaster. Genet 1999, 151(2):725-737.

17. Seong KH, Ogashiwa T, Matsuo T, Fuyama Y, Aigaki T: Application of the gene search system to screen for longevity genes in Drosophila. Biogerontology 2001, 2(3):209-217.

18. Laviolette MJ, Nunes P, Peyre JB, Aigaki T, Stewart BA: A genetic screen for suppressors of Drosophila NSF2 neuromuscular junction overgrowth. Genetics 2005, 170(2):779-792.

19. Kanuka H, Hiratou T, Igaki T, Kanda H, Kuranaga E, Sawamoto K, Aigaki T, Okano H, Miura M: Gain-of-function screen identifies a role of the Sec61alpha translocon in Drosophila postmitotic neurotoxicity. Biochim Biophys Acta 2005, 1726(3):225-237.

20. Katsuyama T, Sugawara T, Tatsumi M, Oshima Y, Gehring WJ, Aigaki T, Kurata S: Involvement of winged eye encoding a chromatin-associated bromo-adjacent homology domain protein in disc specification. Proc Natl Acad Sci U S A 2005, 102(44):15918-15923.

21. Zhang D, Zhou W, Yin C, Chen W, Ozawa R, Ang LH, Anandan L, Aigaki T, Hing $\mathrm{H}$ : Misexpression screen for genes altering the olfactory map in Drosophila. Genesis 2006, 44(4):189-201. 
22. Brand $\mathrm{AH}$, Perrimon N: Targeted gene expression as a means of altering cell fates and generating dominant phenotypes. Development 1993 118(2):401-415.

23. Rohn TT, Head E: Caspase activation in Alzheimer's disease: early to rise and late to bed. Rev Neurosci 2008, 19(6):383-393.

24. Devarajan E, Sahin AA, Chen JS, Krishnamurthy RR, Aggarwal N, Brun AM Sapino A, Zhang F, Sharma D, Yang XH, Tora AD, Mehta K: Downregulation of caspase 3 in breast cancer: a possible mechanism for chemoresistance. Oncogene 2002, 21(57):8843-8851.

25. Szabo A, Dalmau J, Manley G, Rosenfeld M, Wong E, Henson J, Posner JB, Furneaux HM: HuD, a paraneoplastic encephalomyelitis antigen, contains RNA-binding domains and is homologous to Elav and Sex-lethal. Cell 1991, 67(2):325-333.

26. Hirvonen-Santti SJ, Rannikko A, Santti H, Savolainen S, Nyberg M, Janne OA, Palvimo JJ: Down-regulation of estrogen receptor beta and transcriptional coregulator SNURF/RNF4 in testicular germ cell cancer. Eur Urol 2003, 44(6):742-747. discussion 747.

27. Pero R, Lembo F, Di Vizio D, Boccia A, Chieffi P, Fedele M, Pierantoni GM, Rossi P, Iuliano R, Santoro M, Viglietto G, Bruni CB, Fusco A, Chiariotti L: RNF4 is a growth inhibitor expressed in germ cells but not in human testicular tumors. Am J Pathol 2001, 159(4):1225-1230.

28. Phelan DR, Price G, Liu YF, Dorow DS: Activated JNK phosphorylates the c-terminal domain of MLK2 that is required for MLK2-induced apoptosis. J Biol Chem 2001, 276(14):10801-10810.

29. Strebhardt K: in PLK (Polo-Like Kinase): Encyclopedia of Molecular Medicine, ed Creighton T E (Wiley, New York); 2001:2530-2532.

30. Hudson ME, Pozdnyakova I, Haines K, Mor G, Snyder M: Identification of differentially expressed proteins in ovarian cancer using high-density protein microarrays. Proc Natl Acad Sci U S A 2007, 104(44):17494-17499.

31. Verkerk AJ, Pieretti M, Sutcliffe JS, Fu YH, Kuhl DP, Pizzuti A, Reiner O, Richards S, Victoria MF, Zhang FP, Eussen B, van Ommen GJ, Blonden L, Riggins G, Chastain J, Kunat C, Galjaard H, Caskey CT, Nelson D, Oostra B, Warren S: Identification of a gene (FMR-1) containing a CGG repeat coincident with a breakpoint cluster region exhibiting length variation in fragile X syndrome. Cell 1991, 65(5):905-914.

32. Liu J, Ghanim M, Xue L, Brown CD, lossifov I, Angeletti C, Hua S, Negre N, Ludwig M, Stricker T, Al-Ahmadie HA, Tretiakova M, Camp RL, Perera-Alberto M, Rimm DL, Xu T, Rzhetsky A, White KP: Analysis of Drosophila segmentation network identifies a JNK pathway factor overexpressed in kidney cancer. Science 2009, 323(5918):1218-1222.

33. Babbar N, Casero RA Jr: Tumor necrosis factor-alpha increases reactive oxygen species by inducing spermine oxidase in human lung epithelial cells: a potential mechanism for inflammation-induced carcinogenesis. Cancer Res 2006, 66(23):11125-11130.

34. Goodwin AC, Jadallah S, Toubaji A, Lecksell K, Hicks JL, Kowalski J, Bova GS, De Marzo AM, Netto GJ, Casero RA Jr: Increased spermine oxidase expression in human prostate cancer and prostatic intraepithelial neoplasia tissues. Prostate 2008, 68(7):766-772.

35. Xu H, Chaturvedi R, Cheng Y, Bussiere Fl, Asim M, Yao MD, Potosky D, Meltzer SJ, Rhee JG, Kim SS, Moss SF, Hacker A, Wang Y, Casero RA Jr, Wilson KT: Spermine oxidation induced by Helicobacter pylori results in apoptosis and DNA damage: implications for gastric carcinogenesis. Cancer Res 2004, 64(23):8521-8525.

36. Bonaglia MC, Giorda R, Tenconi R, Pessina M, Pramparo T, Borgatti R, Zuffardi O: A 2.3 Mb duplication of chromosome 8q24.3 associated with severe mental retardation and epilepsy detected by standard karyotype. Eur J Hum Genet 2005, 13(5):586-591.

37. Hosoya N, Qiao Y, Hangaishi A, Wang L, Nannya Y, Sanada M, Kurokawa M, Chiba S, Hirai H, Ogawa S: Identification of a SRC-like tyrosine kinase gene, FRK, fused with ETV6 in a patient with acute myelogenous leukemia carrying a $\mathrm{t}(6 ; 12)(\mathrm{q} 21 ; \mathrm{p} 13)$ translocation. Genes Chromosomes Cancer 2005, 42(3):269-279.

38. Baum JS, Arama E, Steller H, McCall K: The Drosophila caspases Strica and Dronc function redundantly in programmed cell death during oogenesis. Cell Death Differ 2007, 14(8):1508-1517.

39. Liu YF, Dorow D, Marshall J: Activation of MLK2-mediated signaling cascades by polyglutamine-expanded huntingtin. J Biol Chem 2000, 275(25):19035-19040.

40. Jabbour AM, Ekert PG, Coulson E, Knight MJ, Ashley DM, Hawkins CJ: The p35 relative, p49, inhibits mammalian and Drosophila caspases including DRONC and protects against apoptosis. Cell Death Differ 2002, 9(12):1311-1320.
41. Peterson C, Carney GE, Taylor BJ: White K: reaper is required for neuroblast apoptosis during Drosophila development. Development 2002, 129(6):1467-1476.

42. Vucic D, Kaiser WJ, Harvey AJ, Miller LK: Inhibition of reaper-induced apoptosis by interaction with inhibitor of apoptosis proteins (IAPs). Proc Natl Acad Sci US A 1997, 94(19):10183-10188.

43. Gavrieli $Y$, Sherman Y, Ben-Sasson SA: Identification of programmed cell death in situ via specific labeling of nuclear DNA fragmentation. J Cell Biol 1992, 119(3):493-501.

44. Huang X, Warren JT, Buchanan J, Gilbert LI, Scott MP: Drosophila NiemannPick type C-2 genes control sterol homeostasis and steroid biosynthesis: a model of human neurodegenerative disease. Development 2007, 134(20):3733-3742.

45. McGuire SE, Le PT, Osborn AJ, Matsumoto K, Davis RL: Spatiotemporal rescue of memory dysfunction in Drosophila. Science 2003, 302(5651):1765-1768.

46. Ashburner M, Ball CA, Blake JA, Botstein D, Butler H, Cherry JM, Davis AP, Dolinski K, Dwight SS, Eppig JT, Harris MA, Hill DP, Issel-Tarver L, Kasarskis A, Lewis S, Matese JC, Richardson JE, Ringwald M, Rubin GM, Sherlock G: Gene ontology: tool for the unification of biology. Gene Ontology Consortium Nat Genet 2000, 25(1):25-29.

47. Eisenberg $E$, Levanon EY: Human housekeeping genes are compact. Trends Genet 2003, 19(7):362-365.

48. Martin-Bermudo MD, Dunin-Borkowski OM, Brown NH: Specificity of PS integrin function during embryogenesis resides in the alpha subunit extracellular domain. EMBO J 1997, 16(14):4184-4193.

49. Michelson AM: Muscle pattern diversification in Drosophila is determined by the autonomous function of homeotic genes in the embryonic mesoderm. Development 1994, 120(4):755-768.

50. Green RB, Hatini $V$, Johansen KA, Liu XJ, Lengyel JA: Drumstick is a zinc finger protein that antagonizes Lines to control patterning and morphogenesis of the Drosophila hindgut. Development 2002, 129(15):3645-3656

51. Iwaki DD, Lengyel JA: A Delta-Notch signaling border regulated by Engrailed/Invected repression specifies boundary cells in the Drosophila hindgut. Mech Dev 2002, 114(1-2):71-84.

52. Hozumi S, Maeda R, Taniguchi K, Kanai M, Shirakabe S, Sasamura T, Speder P, Noselli S, Aigaki T, Murakami R, Matsuno K: An unconventional myosin in Drosophila reverses the default handedness in visceral organs. Nature 2006, 440(7085):798-802

53. Tian C, Gao B, Fang Q, Ye G, Zhu S: Antimicrobial peptide-like genes in Nasonia vitripennis: a genomic perspective. BMC Genomics 2010, 11:187.

54. Villa P, Kaufmann SH, Earnshaw WC: Caspases and caspase inhibitors. Trends Biochem Sci 1997, 22(10):388-393.

doi:10.1186/1471-2156-15-46

Cite this article as: Nakayama et al:: A gain-of-function screen to identify genes that reduce lifespan in the adult of Drosophila melanogaster. BMC Genetics 2014 15:46.

\section{Submit your next manuscript to BioMed Central and take full advantage of:}

- Convenient online submission

- Thorough peer review

- No space constraints or color figure charges

- Immediate publication on acceptance

- Inclusion in PubMed, CAS, Scopus and Google Scholar

- Research which is freely available for redistribution 